\title{
Mortality among patients with hypertension from 1995 to 2005: a population-based study
}

\author{
Karen Tu MD MSc, Zhongliang Chen MD MSc, Lorraine L. Lipscombe MD MSc, for the Canadian \\ Hypertension Education Program Outcomes Research Taskforce
}

$\infty$

See related articles, pages I429, I44I and I458

\section{ABSTRACT}

Background: We have reported that the prevalence of diagnosed hypertension increased by 60\% from 1995 to 2005 in Ontario. In the present study, we asked whether this increase is explained by a decrease in the mortality rate.

Methods: We performed a population-based cohort study using linked administrative data for Ontario, a Canadian province with over 12 million residents. We identified prevalent cases of hypertension using a validated case-definition algorithm for hypertension, and we examined trends in mortality from 1995 to 2005 among adults aged 20 years and older with hypertension.

Results: The age- and sex-adjusted mortality among patients with hypertension decreased from 11.3 per 1000 people in 1995 to 9.6 per 1000 in $2005(p<0.001)$, which is a relative reduction of $15.5 \%$. We found that the relative decrease in age-adjusted mortality was higher among men than among women $(-22.2 \%$ v. $-7.3 \%, p<0.001)$.

Interpretation: Mortality rates among patients with hypertension have decreased. Along with an increasing incidence, decreased mortality rates may contribute to the increased prevalence of diagnosed hypertension. Sex-related discrepancies in the reduction of mortality warrant further investigation.

Une version française de ce résumé est disponible à l'adresse www.cmaj.ca/cgi/content/full/I78/II/I436/DCI

CMAJ 2008;178(II):1436-40

$\mathrm{H}$ igh blood pressure is the leading risk factor for mortality around the world., 1,2 Over a decade ago, the Canadian Heart Health Survey reported that $42 \%$ of Canadian adults with hypertension were unaware that they had the condition and that only $\mathrm{r} 6 \%$ of cases were treated and controlled. ${ }^{3}$ More recent studies in the United States ${ }^{4}$ and England ${ }^{5}$ have reported improved awareness, treatment and control among adults with hypertension. In addition, increased initiation of hypertensive medications among elderly patients ${ }^{6}$ and increased use of polytherapy for treating hypertension have been reported. ${ }^{7}$ Given that blood pressure control has been shown to reduce mortality, one might expect that enhanced awareness and treatment of hypertension has led to improvements in mortality among patients with this condition. Greater survival of patients with hypertension would contribute to an overall increase in the prevalence of hypertension.

In another article in this issue of $C M A J$, we report that the prevalence of diagnosed hypertension among adults increased by $60 \%$ from 1995 to 2005 , which greatly surpassed prior projections for the developed world. ${ }^{8}$ Previous projections may have underestimated prevalence ${ }^{9}$ because researchers did not adequately account for the contribution of increased survival. Indeed, the increased prevalence cannot be explained by increased incidence alone, because the incidence of hypertension increased by $25.7 \%$ between 1997 and 2004 whereas prevalence increased by $35.5 \%$ during that same period. In the present study, our objective was to examine the mortality rates among patients with hypertension to determine whether declining mortality also contributed to the rising prevalence of hypertension.

\section{Methods}

\section{Study population and data sources}

Ontario is Canada's most populous province, with over 12 million residents. Ontario has high ethnic diversity, and $85 \%$ of its residents live in urban areas. ${ }^{10}$ Ontario has a universal single-payer health care system that covers all physician and hospital services. We identified patients with hypertension from 1995 to $2000^{8}$ through linked administrative databases using a validated algorithm for identifying patients with hypertension. ${ }^{11}$

We obtained annual mortality rates for patients with hypertension from the Registered Persons database, which contains death-certificate information as well as demographic and residential information for all Ontario residents eligible for health coverage. We confirmed deaths using the hospitalization database from the Canadian Institute for Health Information and data from the Ontario Cancer Reg-

From the Institute for Clinical Evaluative Sciences (Tu, Chen, Lipscombe); and the Departments of Family and Community Medicine (Tu) and Medicine (Lipscombe), University of Toronto, Toronto, Ont. 
istry. In cases where discrepancies about the date of death occurred, the Canadian Institute for Health Information or Ontario Cancer Registry date was used.

This study received ethics approval from the institutional review board at Sunnybrook Health Sciences Centre, Toronto, Ont.

\section{Statistical analysis}

We calculated annual mortality rates by dividing the number of deaths among patients with hypertension by the number of people with hypertension (annual incident and prevalent cases from the previous year). Mortality rates are presented according to the end of the fiscal periods. To compare hypertension mortality rates in 1995 to those in 2005, we standardized all rates by age and sex according to the 200I Canadian census data. ${ }^{12}$ For comparison of rates between men and women, we standardize all rates by age using 200I Canadian census data. We calculated the percentage change in mortality rates between years by dividing the difference between the 2 rates by the earlier rate and multiplying by roo.

We used logistic regression to test for differences in mortality for each fiscal year and to examine the effect of age and sex on mortality. The effects of fiscal year, age and sex were assessed using multivariable logistic regression. We compared mortality rates between men and women and age using $\chi^{2}$ analyses. Cochran-Mantel-Haenszel and Breslow-Day tests were used to compare mortality changes between age and sex strata. We used the Cochran-Armitage Trend test to examining the declining trend of crude mortality over time.

To examine comorbidities that may have affected mortality rates, we identified patients with diabetes using the Ontario Diabetes Database. ${ }^{13}$ We identified patients who were listed in this database before the start of the fiscal year for patients who were alive, and we identified those who were listed in the database before their date of death for patients who died in the fiscal years I995, 2000 and 2005. Similarly, we calculated Charlson Comorbidity Index scores ${ }^{14}$ in the I-year period before the start of the fiscal year for patients who were alive. For patients who had died, we calculated this score in the I-year before the date of death. In addition, using previously developed methods ${ }^{15}$ we compared mortality among patients with a history of cardiovascular disease (including acute myocardial infarction, angina, congestive heart failure, coronary artery bypass graft surgery, coronary catheterization or percutaneous transluminal coro-

Table 1: Mortality rate per 1000 people with prevalent hypertension in 1995, 2000 and 2005

\begin{tabular}{|c|c|c|c|c|c|c|c|}
\hline \multirow[b]{2}{*}{ Year } & \multicolumn{5}{|c|}{ Age, yr } & \multicolumn{2}{|c|}{ All ages } \\
\hline & $20-34$ & $35-49$ & $50-64$ & $65-74$ & $\geq 75$ & $\begin{array}{c}\text { Crude* } \\
\text { mortality rate }\end{array}$ & $\begin{array}{c}\text { Adjusted } \dagger \\
\text { mortality rate }\end{array}$ \\
\hline \multicolumn{8}{|l|}{$1995 \ddagger$} \\
\hline No. of deaths & 86 & 627 & 3439 & 7669 & 15291 & 27112 & \\
\hline People with hypertension & 45655 & 192807 & 366487 & 312372 & 222157 & 1139478 & \\
\hline \multicolumn{8}{|l|}{$2000 \ddagger$} \\
\hline No. of deaths & 83 & 859 & 4327 & 9757 & 27346 & 42372 & \\
\hline People with hypertension & 59066 & 284630 & 541991 & 427692 & 382430 & 1695809 & \\
\hline Death rate (per 1000) & 1.4 & 3.0 & 8.0 & 22.8 & 71.5 & 25.0 & 10.7 \\
\hline \multicolumn{8}{|l|}{$2005 \ddagger$} \\
\hline \multicolumn{8}{|l|}{$\begin{array}{l}\text { Change } \\
\text { from } 1995 \text { to } 2005 \text {, } \%\end{array}$} \\
\hline No. of deaths & 2.3 & 61.9 & 57.4 & 32.2 & 140.8 & 97.2 & \\
\hline People with hypertension & 57.5 & 101.4 & 109.6 & 69.9 & 148.4 & 102.8 & \\
\hline Death rate (per 1000) & -35.1 & -19.7 & -24.9 & -22.2 & -3.1 & -2.8 & $-15.5 \S$ \\
\hline \multicolumn{8}{|l|}{$\begin{array}{l}\text { Change in death rage } \\
\text { from } 1995 \text { to } 2005, \neq \%\end{array}$} \\
\hline Women & -33.3 & -16.7 & -20.6 & -18.4 & 3.3 & 4.6 & $-7.3 \rrbracket$ \\
\hline Men & -36.4 & -20.0 & -27.9 & -28.2 & -14.5 & -10.6 & -22.29 \\
\hline
\end{tabular}

*Significant interaction between age-group, sex and year $(p<0.01)$.

†Death rates were age- and sex-adjusted by use of 2001 consensus data.

\#By March 31 of the year shown.

§Significant change $(p<0.001)$ in the death rate after data were adjusted for age and sex.

ISignificant change $(p<0.001)$ in mortality rate after the data were adjusted for age. 
nary angioplasty) in the 5 years before the fiscal year or 5 years before the date of death for the fiscal years 1995,2000 and 2005. We examined the effect of socioeconomic status on mortality rates using neighbourhood income quintiles according to 200 I census data derived from postal code census geography, ${ }^{16,17}$ and we examined the effect of residence location (rural v. urban) on mortality rates using definitions from Statistics Canada. ${ }^{18}$

We used a logistic-regression model to adjust for history of diabetes, Charlson score, 5-year history of cardiovascular diseases, residence location and socioeconomic status. We used Pearson correlation to examine trends in annual multivariable-adjusted mortality rates.

\section{Results}

Overall, the age- and sex-adjusted mortality rate among people with hypertension decreased from II.3 per Iooo adults with hypertension in 1995 to 9.6 per 1000 in 2005 , resulting in a relative decrease in mortality of over $15.5 \%$. Among both men and women, the largest decrease was among those aged 20-34 years and the smallest decrease was among those aged 75 years and older (Table I). The difference between the changes in mortality rates from 1995 to 2005 between men and women increased with age, with a 3.0\% difference in the youngest age category and a $17.8 \%$ difference in the oldest age category. Mortality rates were higher among men than among women throughout the study period. There was a larger decrease in multivariable-adjusted mortality among men than among women from 1995 to 2005 (Figure I).

Among patients with hypertension (including both those who died and those who were alive in 1995, 2000 and 2005), we found an increase in the rate of comorbidities over time (Table 2). We found increases in the number of patients with diabetes, a Charlson score of $2+$ and with a history of cardiovascular disease. Among patients who died, more were in the lower socioeconomic income quintiles; however, the difference in mortality rates between income quintiles decreased over time. The mortality rate among patients living in rural areas decreased minimally (Table 2).

\section{Interpretation}

In this population-based study, we found a $15.5 \%$ relative reduction in mortality rates between 1995 and 2005 among patients with hypertension. Our findings suggest that the rise in hypertension prevalence reported in our other study ${ }^{8}$ was because of an increase in incidence and a decline in mortality. It is also possible that physicians are improving their detection of hypertension and are detecting it earlier, thereby also contributing to the increasing prevalence. Previous projections for increasing prevalence in developed countries ${ }^{9}$ were likely underestimated because they did not take into account the contribution of all of these factors.

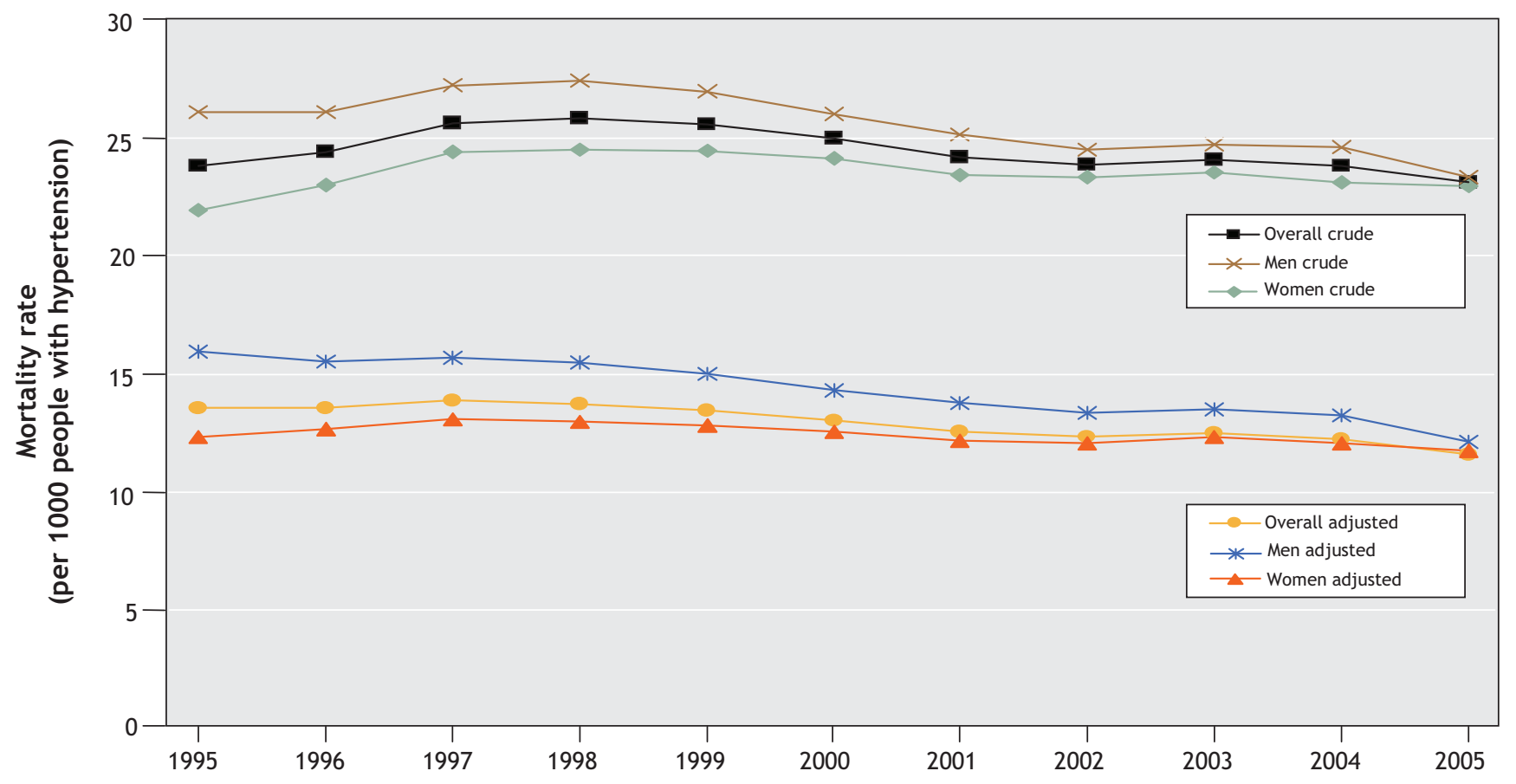

Fiscal year

Figure 1: Annual crude and multivariable adjusted mortality rates among people with hypertension. Yearly rates are based on death by Mar. 31 of each year. Data were adjusted by logistic regression for age, sex, rural residence location, socioeconomic status, diabetes, 5 year history of cardiovascular disease, Charlson score and interaction between age and sex. The adjusted trends for overall and men were significant $(p<0.001)$, as was the adjusted trend for women $(p<0.012)$. 
Table 2: Characteristics of patients with prevalent hypertension in 1995, 2000 and 2005, by survival status

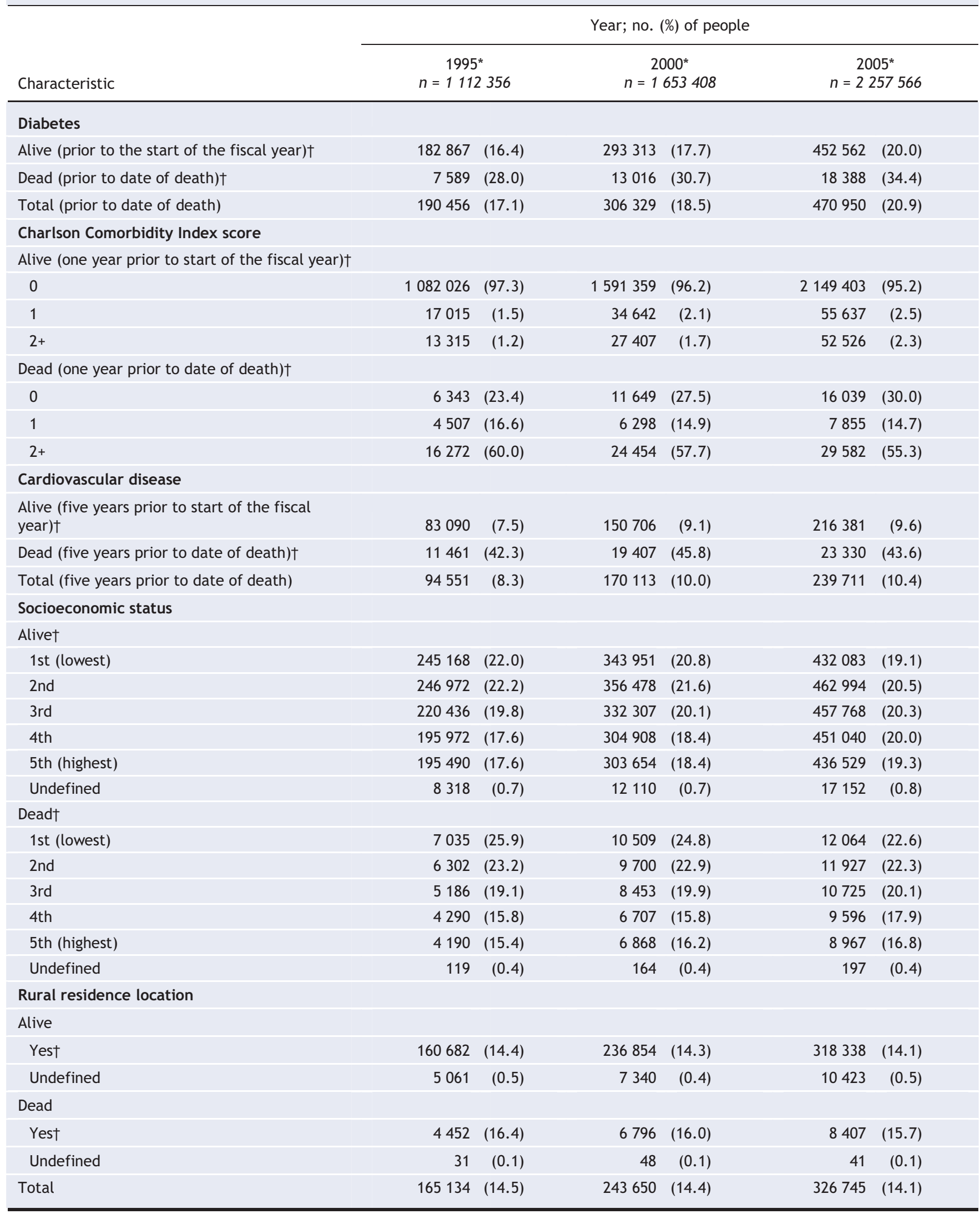


Despite the increasing presence of comorbidities among patients with hypertension, the decrease in mortality rates suggests that patients with hypertension are increasingly receiving appropriate treatment, thus preventing death. Although we were unable to include prescribing data for patients aged 65 years or less, studies examining prescribing patterns and rates among elderly patients ${ }^{6,7}$ support the likelihood that these patients are increasingly receiving antihypertensive medications that improve survival.

Whether the observed decrease in mortality among patients with hypertension was caused by decreased cardiovascular mortality cannot be determined with the available administrative data because cause of death is not reliably recorded. ${ }^{19}$

Although mortality rates among men with hypertension are higher than among women, the gap between the rates has narrowed over time. The differences in mortality rates between men and women were more pronounced in the older age groups. Studies have reported undertreatment of hypertension among older people after acute myocardial infarction ${ }^{20}$ and more aggressive treatment in men with acute myocardial infarction compared with women; however, no previous study has found a difference in long-term mortality. ${ }^{21}$ Whether hypertension in men or younger people is being treated more aggressively or managed differently warrants further investigation.

The overall decrease in mortality rates among patients with diagnosed hypertension is encouraging. Future research should focus on determining whether sex-related discrepancies in treatment account for the substantially lower decrease in mortality rates among women with hypertension.

This article has been peer reviewed.

Competing interests: None declared.

Contributors: Each of the authors contributed to the study design, and the analysis and interpretation of data. Zhongliang Chen acquired the data. Karen Tu wrote the manuscript and, along with Zhongliang Chen and Lorraine Lipscombe, revised it critically for important intellectual content. Each of the authors approved the final verion submitted for publication.

Acknowledgements: We thank Dr. Finlay A. McAlister and Dr. Norman R.C. Campbell for their review of and input into this manuscript.

This research was supported by a Grant-in-Aid from the Heart and Stroke Foundation of Ontario (grant \#NA 5459). The Heart and Stroke Foundation had no role in the design or conduct of the study; the collection, manage- ment, analysis or interpretation of the data; or the preparation, review or approval of the manuscript.

Dr. Lipscombe is funded by a Clinician-Scientist award from the Canadian Diabetes Association and the Canadian Institutes of Health Research.

\section{REFERENCES}

I. Ezzati M, Lopex AD, Rodgers A, et al. Selected major risk factors and global and regional burden of disease. Lancet 2002;360:1347-60.

2. World Health Organization. The World Health Report 2002. Geneva: The Organization; 2002.

3. Joffres MR, Ghadirian P, Fodor JG, et al. Awareness, treatment, and control of hypertension in Canada. Am J Hypertens 1997;10:1097-I02.

4. Hajjar I, Kotchen TA. Trends in prevalence, awareness, treatment and control of hypertension in the United States, I988-2000. JAMA 2003;290:199-206.

5. Primatesta P, Poulter NR. Improvement in hypertension management in England: results from the Health Survey for England 2003. J Hypertens 2006;24:1187-92.

6. Tu K, Campbell NR, Duong-Hua M, et al. Hypertension management in the elderly has improved. Ontario Prescribing Trends, I994 to 2002. Hypertension 2005;45:III3-8.

7. Campbell NR, McAlister FA, Duong-Hua M, et al. Polytherapy with two or more antihypertensive drugs to lower blood pressure in elderly Ontarians. Room for improvement. Can J Cardiol 2007;23:783-7.

8. Tu K, Chen Z, Lipscombe LL. Prevalence and incidence of hypertension from I995 to 2005: a population-based study. CMAJ 2008;178:1429-35

9. Kearney PM, Whelton M, Reynolds K, et al. Global burden of hypertension: analysis of worldwide data. Lancet 2005;365:217-23.

Io. Statistics Canada. Census of Population, I85I-200I. Ottawa: Statistics Canada; 2007.

II. Tu K, Campbell NRC, Chen Z, et al. Accuracy of administrative databases in identifying patients with hypertension. Open Medicine 2007;1:e5-7.

I2. Statistics Canada. Annual demographic statistics. Ottawa: Statistics Canada; 2005.

I3. Hux JE, Ivis F, Flintoft V, et al. Diabetes in Ontario: determination of prevalence and incidence using a validated administrative data algorithm. Diabetes Care 2002;25:512-6.

I4. Deyo RA, Cherkin DC, Ciol MA. Adapting a clinical comorbidity index for use with ICD-9-CM administrative databases. J Clin Epidemiol 1992;45:613-9.

I5. Lipscombe LL, Gomes T, Levesque L, et al. Thiazolidinediones and cardiovascular outcomes in older patients with diabetes. JAMA 2007;298:2634-43.

I6. Wilkins R. PCCF+ version 4 J user's guide: automated geographic coding based on the Statistics Canada postal code conversion files, including postal codes through September 2006. Ottawa: Statistics Canada; 2007

17. Mustard CA, Derksen S, Berthelot JM, et al. Assessing ecologic proxies for household income: A comparison of household and neighbourhood level income measures in the study of population health status. Health Place I999;5:157-71.

I8. du Plessis V, Beshiri R, Bollman R, et al. Definitions of "rural."[Agriculture and rural working paper series]. Ottawa: Statistics Canada; 2002. Available: www.statcan.ca /english/research/2I-60I-MIE/2I-6oI-MIE200206I.htm (accessed 2008 April 8).

I9. Manuel DG, Schultz SE. Health-related quality of life and healht-adjusted life expectancy of people with diabetes in Ontario, Canada, 1996-1997. Diabetes Care 2004;27:407-I4.

20. Hanratty B, Lawlor DA, Robinson MB, et al. Sex differences in risk factors, treament and mortality after acute myocardial infarction: an observational study. J Epidemiol Community Health 2000;54:912-6.

2I. Gottlieb S, Harpaz D, Shotan A, et al. Sex differences in management and outcome after acute myocardial infarction in the Ig9os: a prospective observational community-based study. Israeli Thrombolytic Survey Group. Circulation 2000;I02:2484-90.

Correspondence to: Dr. Karen Tu, Institute for Clinical Evaluative Sciences, Rm. GIo8, 2075 Bayview Ave., Toronto ON M4N 3M5; fax 4I6 480-6o48; karen.tu@ices.on.ca 